\title{
A New Case of Beckwith-Wiedemann Syndrome with an 11 p15 Duplication of Paternal Origin [46,XY,-21,+der(21), t(11;21)(p15.2;q22.3)pat]
}

\author{
M. Krajewska-Walasek, A. Gutkowska, M. Mospinek-Krasnopolska, \\ K. Chrzanowska \\ Department of Genetics, Memorial Hospital-Child Health Center, Warsaw, Poland
}

\begin{abstract}
We present a new case of $11 \mathrm{p} 15$ duplication (trisomy $11 \mathrm{p} 15$ ) in a boy $[46, X Y,-21,+$ der $(21), t(11 ; 21)(p 15.2 ; q 22.3)]$ suffering from Beckwith-Wiedemann syndrome (BWS), whose phenotypically normal father carries a balanced translocation between chromosomes 11 and $21[46, \mathrm{XY}, \mathrm{t}(11 ; 21)(\mathrm{p} 15.2 ; \mathrm{q} 22.3)]$. The paternal grandmother has the same balanced translocation and is also clinically normal. BWS was suspected when the boy was 6 months old because of gigantism, macroglossia, visceromegaly, ear lobe creases and abdominal distention. Apart from the characteristic BWS phenotype, the boy has other features which are almost exclusively observed in $11 \mathrm{p}$ trisomy (high forehead with frontal upsweep of hair, wide central nose bridge, slightly beaked nose, chubby cheeks and severe mental retardation). So far, at least eight cases of $11 \mathrm{p} 15$ duplication have been described as patients with BWS. In six of these, the duplication was due to inheritance of a translocated or rearranged paternal chromosome. This was also the case in our patient. In the two other previously published cases, the 11 p 15 duplications were de novo, but in one of these, DNA analysis has subsequently shown that the duplication was of paternal origin. We discuss our observations in relation to the above-mentioned previous cases of $11 \mathrm{p} 15$ duplication and the possible role of genomic imprinting in the etiology of BWS.
\end{abstract}

Key words: Beckwith-Wiedemann syndrome, Translocation (11;21), Duplication 11p15, Trisomy 11p, Genomic imprinting

We report on a new case of $11 \mathrm{p} 15$ duplication (trisomy $11 \mathrm{p} 15$ ) in a boy $[46, X Y, 21,+\operatorname{der}(21), t(11 ; 21)(\mathrm{p} 15.2 ; \mathrm{q} 22.3)]$ suffering from Beckwith-Wiedemann syndrome (BWS), whose phenotypically normal father carries a balanced translocation between chromosomes 11 and 21 [46,XY,t(1 1;21)(p15.2;q22.3)]. The paternal grandmother has the same balanced translocation and is also clinically normal. 


\section{Case Report}

BG, a boy, the second child of healthy and unrelated parents (mother aged 28 and father aged 31 at the time of his birth) was delivered at 38 weeks gestation. All birth measurements were above the 90th centile: birth weight was $3,700 \mathrm{~g}$, length $60 \mathrm{~cm}$ and head circumference $36 \mathrm{~cm}$. The pregnancy and delivery were normal. Healthy sibs were born from the first and third pregnancies. After the birth, the boy was hypotonic and was described as having a large tongue, malformed ears, abdominal distention, and enlargement of the liver and spleen. There was no neonatal hypoglycemia but he suffered from prolonged neonatal icterus. Psychomotor developmental delay was observed from the very beginning. At the age of 3 months, he was admitted to hospital for pneumonia and respiratory distress syndrome.

The boy was seen for the first time by us when he was 6 months old. His height was $67.8 \mathrm{~cm}$ (25-50th percentile), weight $6,600 \mathrm{~g}$ ( $<3 \mathrm{rd}$ centile), and head circumference 41.5 $\mathrm{cm}$ ( $<3 \mathrm{rd}$ centile). He was hypotonic and had an asymmetric, microcephalic head with prominent occiput. His face was large and flat. Facial dysmorphism included a prominent forehead with supraorbital constriction, short horizontal palpebral fissures, slight hypertelorism, epicanthal folds, long nose with a broad, flat bridge and short septum, rounded cheeks, prominent philtrum with well-defined thin margins, prominent lower lip, large tongue, high arched palate, microretrognathia, and a short neck. In addition, he had small, low-set, posteriorly rotated ears with thick, irregular helices and bilateral lobe grooves. His hands were small, soft with short fingers and bilateral transverse palmar

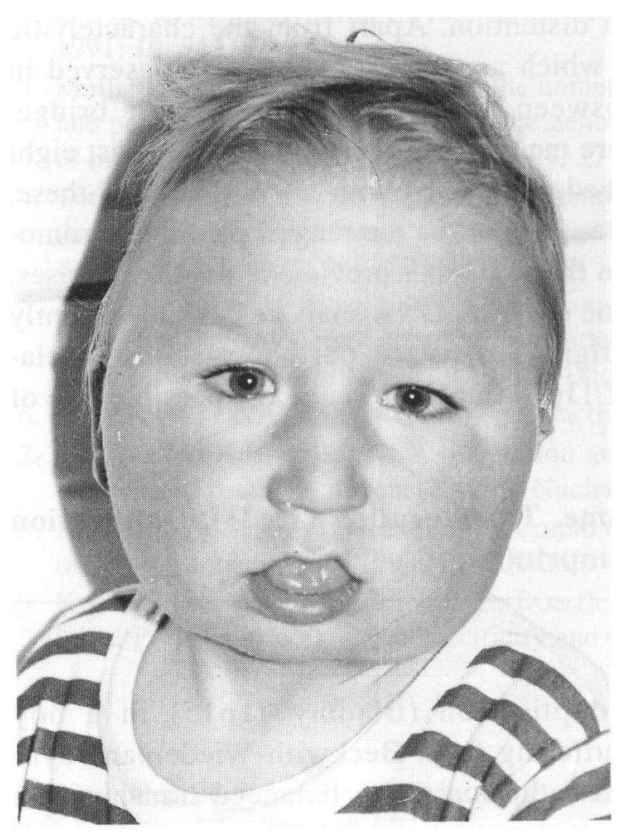

Fig. 1 - The patient BG at the age of 2.5 years.

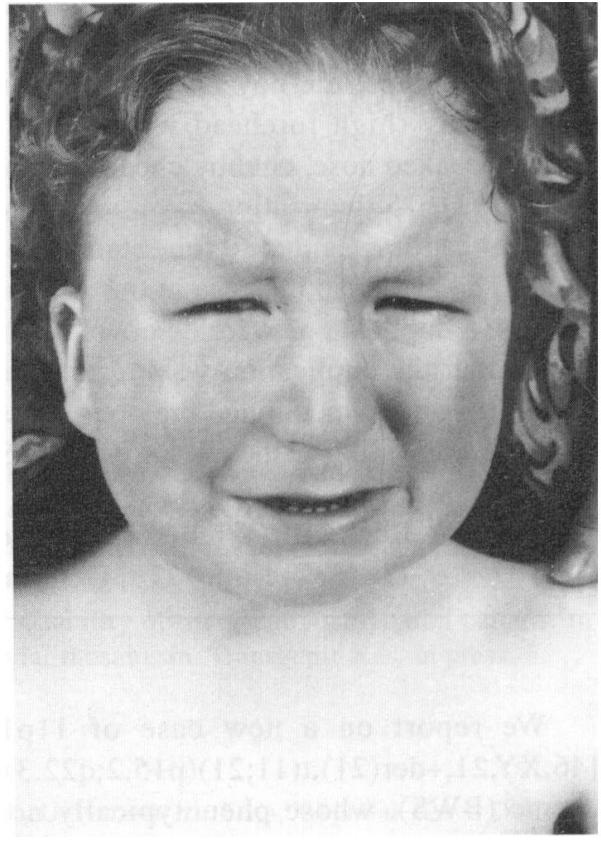

Fig. 2 - The patient BG at the age of 3.5 years. 
creases. His feet were flat, broad with relatively long and wide toes and hypoplastic, deep-set nails. Because of the above-mentioned features and large birth measurements, BWS was suspected. Cardiac auscultation, electrocardiogram, chest X-ray, abdominal ultrasound, CT scan of head, routine blood test, metabolic screening results were normal.

The boy was reevaluated at 2.5 (Fig. 1) and 3.5 (Fig. 2) years of age. When tested,
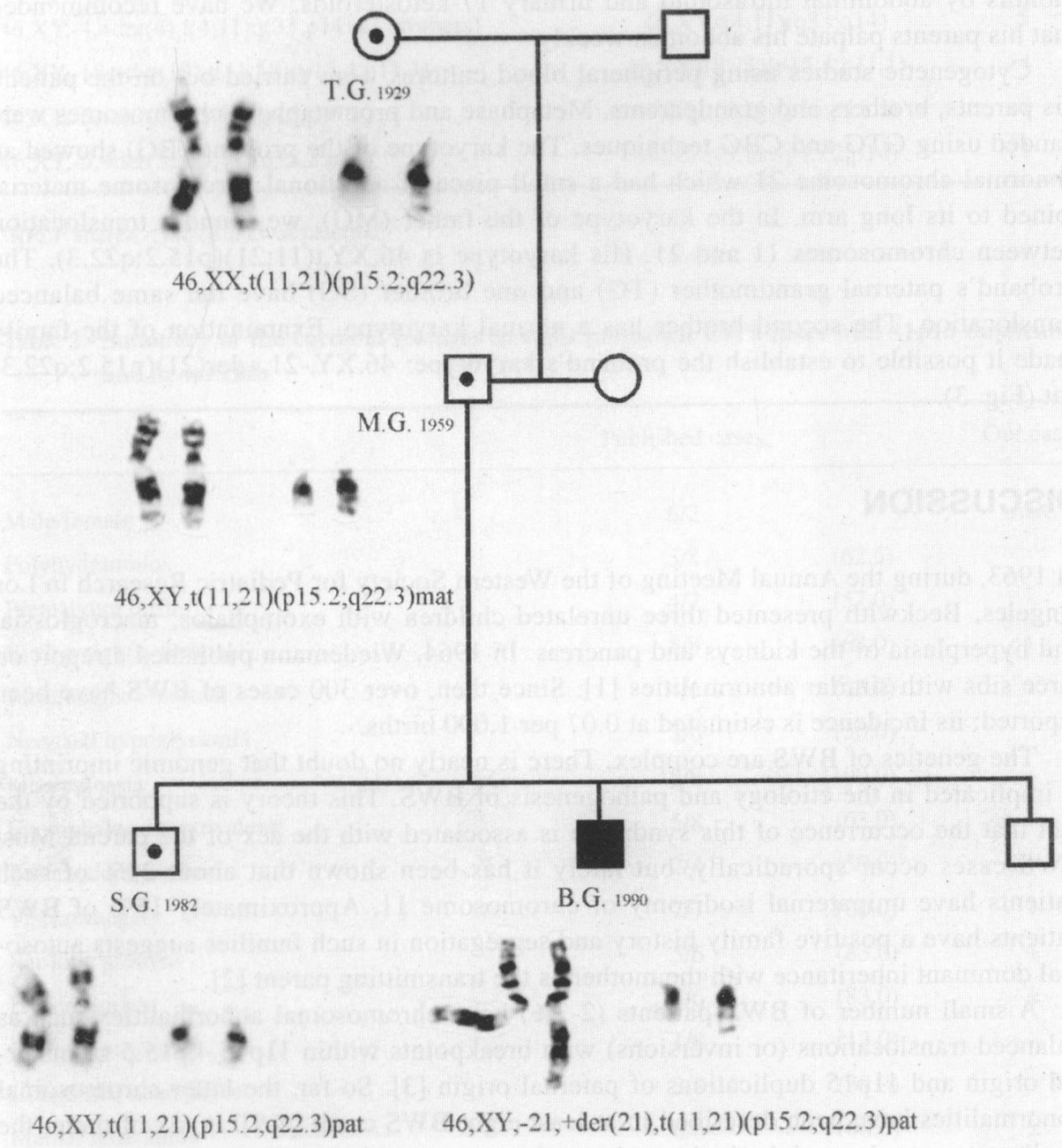
Female
1 Affected
$\square$ Male
- -1 Carriers

Fig. 3 - The pedigree of the family $G$ with partial karyotypes (Gbands). 
his height was at the 90th percentile, weight above the 97th percentile and head circumference was normal for his calendar age. His facial phenotype had changed somewhat with age and was not so unusual. He had a high, convex forehead with frontal upsweep of hair, periorbital fullness of subcutaneous tissues, bulbous and slightly beaked nose, broad chest with widely spaced nipples and mild pectus excavatum, lumbar scoliosis, and small umbilical hernia. Psychological evaluation showed an IQ of 78 (Terman-Merrill test). There was no evidence of visceromegaly. He is now followed up every 6 months by abdominal ultrasound and urinary 17-ketosteroids. We have recommended that his parents palpate his abdomen weekly.

Cytogenetic studies using peripheral blood cultures were carried out on the patient, his parents, brothers and grandparents. Metaphase and prometaphase chromosomes were banded using GTG and CBG techniques. The karyotype of the proband (BG) showed an abnormal chromosome 21 which had a small piece of additional chromosome material joined to its long arm. In the karyotype of the father (MG), we found a translocation between chromosomes 11 and 21 . His karyotype is $46, X Y, t(11 ; 21)(p 15.2 ; q 22.3)$. The proband's paternal grandmother (TG) and one brother ( $\mathrm{SG}$ ) have the same balanced translocation. The second brother has a normal karyotype. Examination of the family made it possible to establish the proband's karyotype: 46,XY,-21,+der(21)(p15.2;q22.3) pat (Fig. 3).

\section{DISCUSSION}

In 1963, during the Annual Meeting of the Western Society for Pediatric Research in Los Angeles, Beckwith presented three unrelated children with exomphalos, macroglossia, and hyperplasia of the kidneys and pancreas. In 1964, Wiedemann published a report on three sibs with similar abnormalities [1]. Since then, over 300 cases of BWS have been reported; its incidence is estimated at 0.07 per 1,000 births.

The genetics of BWS are complex. There is nearly no doubt that genomic imprinting is implicated in the etiology and pathogenesis of BWS. This theory is supported by the fact that the occurrence of this syndrome is associated with the sex of the parent. Most BWS cases occur sporadically, but lately it has been shown that about $20 \%$ of such patients have unipaternal isodisomy of chromosome 11. Approximately $15 \%$ of BWS patients have a positive family history and segregation in such families suggests autosomal dominant inheritance with the mother as the transmitting parent [2].

A small number of BWS patients $(2-3 \%)$ have chromosomal abnormalities such as balanced translocations (or inversions) with breakpoints within $11 \mathrm{p} 15.4, \mathrm{p} 15.5$ of maternal origin and $11 \mathrm{p} 15$ duplications of paternal origin [3]. So far, the latter chromosomal abnormalities have been described in at least eight BWS cases [4-9]. In six of them, the duplication was due to inherited translocated or rearranged patemal chromosomes. In the other two previously published cases, the $11 \mathrm{p} 15$ duplications were de novo, but in one of these, DNA analysis has subsequently shown that the duplication was of paternal origin (Table 1).

Table 2 summarizes the clinical features in eight published BWS cases with $11 \mathrm{p} 15$ duplication and in our case. Our patient has most of the clinical features present in the previous patients. 
Table 1 - Case of BWS with duplications of chromosome $11 \mathrm{p} 15$

\begin{tabular}{lcc}
\hline Karyotype of patient & Karyotype of father & References \\
\hline $46, \mathrm{XY}, \operatorname{rec}(11), \operatorname{dup}(\mathrm{p} 13 \rightarrow \mathrm{p} 15), \operatorname{del}(\mathrm{q} 23 \rightarrow \mathrm{q} 25)$ & $46, \mathrm{XY}, \operatorname{inv}(11)(\mathrm{p} 13 ; \mathrm{q} 23.3)$ & 8 \\
$46, \mathrm{XX}, \operatorname{dup}(11 \mathrm{p})$ & normal & 8 \\
$46, \mathrm{XX}, \operatorname{dup}(11 \mathrm{p} 15)$ & normal $^{\mathrm{a}}$ & 5 \\
$46, \mathrm{XY},-4,+\operatorname{der}(4), \mathrm{t}(4 ; 11) \mathrm{q}(33 ; \mathrm{p} 14)(2$ brothers $)$ & $46, \mathrm{XY}, \mathrm{t}(4 ; 11)(\mathrm{q} 33 ; \mathrm{q} 14)$ & 5 \\
$46, \mathrm{XY},-18,+\operatorname{der}(18), \mathrm{t}(11 ; 18)(\mathrm{p} 15.4 ; \mathrm{p} 11.1)$ & $46, \mathrm{XY}, \mathrm{t}(8 ; 11)(\mathrm{p} 15.4 ; \mathrm{p} 11.1)$ & 4 \\
$46, \mathrm{XY},-5,+\operatorname{der}(5), \mathrm{t}(5 ; 11)(\mathrm{p} 15 ; \mathrm{p} 15.1)$ & $46, \mathrm{XY}, \mathrm{t}(5 ; 11)(\mathrm{p} 15 ; \mathrm{p} 15.1)$ & 7 \\
$46, \mathrm{XY},-5,+\operatorname{der}(5), \mathrm{t}(5 ; 11)(\mathrm{q} 15.2 ; \mathrm{p} 14)$ & $46, \mathrm{XY}, \mathrm{t}(5 ; 11)(\mathrm{p} 15.2 ; \mathrm{p} 14)$ & 1 \\
\hline
\end{tabular}

${ }^{a}$ RFLP analysis: dup(p15) was paternal.

Table 2 - Summary of the cardinal features in eight published BWS cases with 11 p15 duplication and in our case

\begin{tabular}{lccc}
\hline & Published cases & & Our case \\
\hline Male/female & $6 / 2$ & & male \\
Polyhydramnios & $5 / 8$ & $(62.5)$ & - \\
Prematyure birth & $4 / 7$ & $(57.0)$ & - \\
Birth weight $>$ normal & $5 / 8$ & $(63.0)$ & + \\
Birth lenght $>$ normal & $4 / 6$ & $(67.0)$ & + \\
Neonatal hypoglycemia & $3 / 6$ & $(50.0)$ & - \\
Macroglossia & $8 / 8$ & $(100.0)$ & + \\
Exomphalos or equivalent & $5 / 8$ & $(63.0)$ & + \\
Postnatal gigantism & $2 / 4$ & $(50.0)$ & + \\
Visceromegaly & $7 / 7$ & $(100.0)$ & + \\
Ear lobe grooves & $5 / 6$ & $(83.0)$ & + \\
Hypertelorism & $5 / 6$ & $(83.0)$ & \pm \\
Cleft lip or palate & $1 / 8$ & $(13.0)$ & - \\
Congenital heart defect & $3 / 8$ & $(38.0)$ & - \\
Mental retardation & $6 / 6$ & $(100.0)$ & \pm \\
Seizures & $2 / 8$ & $(25.0)$ & - \\
\hline
\end{tabular}

Values in parentheses are percentuage. Other findings:

nevus flammeus (1), increased LDHA and LAT (1), renal malformation (1), ovarian hernia (1), inguinal hernia (1), hypospadias (1), spina bifida (1), adrenocortical cytomegaly (1), pancreatic hypertrophy of islet cells (1), biliary hypoplasia (1), hypotonia (2) and prominent occiput (1). These latter two features were also present in our case. 
BWS was suspected when the boy was 6 months old because of gigantism, macroglossia, visceromegaly, ear lobe creases and abdominal distention. Apart from the characteristic BWS phenotype, the boy has other features which are almost exclusively observed in $11 \mathrm{p}$ trisomy (high forehead with frontal upsweep of hair, wide central nose bridge, slightly beaked nose, chubby cheeks and borderline mental retardation).

Our patient, as have most patients with BWS and duplications of $11 \mathrm{p} 15$, inherited the duplicated region of $11 \mathrm{p}$ from his father. The genes that are responsible for this syndrome are located in region $11 \mathrm{p} 15.5$ and genomic imprinting in this region has been proposed: the paternally derived genes are selectively expressed while the maternally transmitted gene is inactive. The insulin-like growth factor II (IGF2) gene located at $11 \mathrm{p} 15.5$ is now treated as a prime gene candidate, since it is paternally expressed and present at high levels in Wilms' tumor. The second candidate gene, H19, is maternally expressed but its function is still unclear [2].

In our case, duplication of the region $11 \mathrm{p} 15$ increases dosage of paternally derived genes and leads to the BWS phenotype.

\section{REFERENCES}

1. de Grouchy J, Turleau C: Atlas des maladies chromosomique. Paris, Expansion Scientifique Française, 1982, pp. 212-213.

2. Elliot M, Maher ER: Beckwith Wiedemann syndrome. J Med Genet 1994; 31: 560-564.

3. Tommerup N, Brandt CA, Petersen S, Bolund L, Kamper J: Sex dependent transmission of Beckwith-Wiedemann syndrome associated with a reciprocal translocation $\mathrm{t}(9 ; 11)(\mathrm{pl} 1.2 ; \mathrm{p} 15.5)$. J Med Genet 1993; 30: 958-961.

4. Waziri M, Patil SR, Hanson JW, Bartley JA: Abnormality of chromosome 11 in patients with features of Beckwith-Wiedemann syndrome. J Pediatr 1983; 102: 873-876.

5. Turleau C, de Grouchy J, Chavin-Colin F, Martelli H, Voyer M, Charlas R: Trisomy 11 pl5 and Beckwith-Wiedemann syndrome: A report of two cases. Hum Genet 1984; 67: 219-221.

6. Joumel H, Lucas J, Allaire C, Le Mee F, Defawe G, Lecomu M, Jouan H, Roussey M, Le Marec B: Trisomy 11q15 and Beckwith-Wiedemann syndrome: Report of two new cases. Ann Genet 1985; 28: 97-101.

7. Turleau C, de Grouchy J: Beckwith-Wiedemann syndrome, Clinical comparison between patients with and without 11p15 trisomy. Ann Génét 1985; 28: 93-96.

8. Wales JKH, Walker V, Moore IE, Clayton PT: Bronze baby syndrome, biliary hypoplasia, incomplete Beckwith-Wiedemann syndrome and partial trisomy 11. Eur J Pediatr 1986; 145: 141-143.

9. Brown KW, Gardner A, Williams JC, Mott MG, Mc Dermott A, Maitland NJ: Patemal origin of $11 \mathrm{pl} 5$ duplications in the Beckwith-Wiedemann syndrome. Cancer Genet Cytogenet 1992; 58: 66-70.

Correspondence: M. Krajeweska-Walasek, Department of Genetics, Memorial-Hospital-Child Health Centre, Al. Dzieci Polskich 20, PL-04-736 Warsaw (Poland). 